\title{
UV polarisation spectroscopy of 1,4-diethynylbenzene
}

Thulstrup, Peter Waaben; Jones, Nykola Clare; Hoffmann, Søren Vrønning; Spanget-Larsen, Jens

Published in:

Molecular Physics

DOI:

10.1080/00268976.2020.1853841

Publication date:

2021

Document Version

Peer reviewed version

Citation for published version (APA):

Thulstrup, P. W., Jones, N. C., Hoffmann, S. V., \& Spanget-Larsen, J. (2021). UV polarisation spectroscopy of 1,4-diethynylbenzene. Molecular Physics, 119(7), [e1853841]. https://doi.org/10.1080/00268976.2020.1853841

\section{General rights}

Copyright and moral rights for the publications made accessible in the public portal are retained by the authors and/or other copyright owners and it is a condition of accessing publications that users recognise and abide by the legal requirements associated with these rights.

- Users may download and print one copy of any publication from the public portal for the purpose of private study or research.

- You may not further distribute the material or use it for any profit-making activity or commercial gain.

- You may freely distribute the URL identifying the publication in the public portal.

Take down policy

If you believe that this document breaches copyright please contact rucforsk@kb.dk providing details, and we will remove access to the work immediately and investigate your claim. 
Note: Snapshot PDF is the proof copy of corrections marked in EditGenie, the layout would be different from typeset PDF and EditGenie editing view.

\title{
Author Queries \& Comments:
}

Q1 : Graphical abstract missing in the document

Response: Graphical abstract is provided with the document

Q2 : Please note that the journal allows a maximum 5 keywords. Please edit keywords accordingly.

Response: Resolved

Q3 : Please note that the Funding section has been created by summarising information given in your acknowledgements. Please correct if this is inaccurate.

Response: Resolved

Q4 : The funding information provided (Grants of beam time on the CD1 beamline at ISA) has been checked against the Open Funder Registry and we failed to find a match. Please check and resupply the funding details.

Response: This is a local grant

Q5 : Please provide missing city for the reference "[26]" references list entry.

Response: Resolved

Q6 : The reference [52] is listed in the references list but is not cited in the text. Please either cite the reference or remove it from the references list.

Response: This reference is now cited in footnote e to Table 1.

RESEARCH ARTICLE

\section{UV polarisation spectroscopy of 1,4- diethynylbenzene}

\author{
MOLECULAR PHYSICS \\ P. W. THULSTRUP ET AL. \\ Peter W. Thulstrup ${ }^{a}$, Nykola C. Jones ${ }^{b}$, Søren V. Hoffmann ${ }^{b}$, iD Jens Spanget-Larsen ${ }^{c}$ \\ a Department of Chemistry, University of Copenhagen, Copenhagen $\varnothing$, Denmark \\ b Department of Physics and Astronomy, Aarhus University, Aarhus C, Denmark \\ c Department of Science and Environment, Roskilde University, Roskilde, Denmark
}

CONTACT Jens Spanget-Larsen Spanget@ruc.dk Department of Science and Environment, Roskilde University, Universitetsvej 1, DK-4000, Roskilde, Denmark

e1853841

Copyright Line: (c) 2020 Informa UK Limited, trading as Taylor \& Francis Group

\section{ABSTRACT}

1,4-diethynylbenzene is investigated by UV linear dichroism polarisation spectroscopy using synchrotron radiation on molecular samples partially aligned in stretched polyethylene. The investigation covers the range from the absorption onset around 32,000 $\mathrm{cm}^{-1}(310 \mathrm{~nm})$ to $58,000 \mathrm{~cm}^{-1}(170 \mathrm{~nm})$ in the far UV. The polarisation spectra lead to resolution of otherwise overlapping spectral features and to experimental symmetry assignments of the observed molecular states. The observed transition moment directions of the differently polarised components of the weak absorption band between 32,000 and 35,000 cm-1 (310 and $285 \mathrm{~nm}$ ) support previously suggested vibronic assignments. The observed bands are compared with electronic transitions computed with TDCAM-B3LYP, CIS and CIS(D). Magnetic Circular Dichroism (MCD) B-terms computed with the semiempirical LCOAO method are also reported. The calculated ordering of electronic states is found to be sensitive to the theoretical model. The absorption in the far UV is predicted to involve the in-plane $\pi$ and $\pi^{*}$ components of the $C \equiv C$ triple bonds and orbitals of mixed valence-Rydberg character. [Q1] 


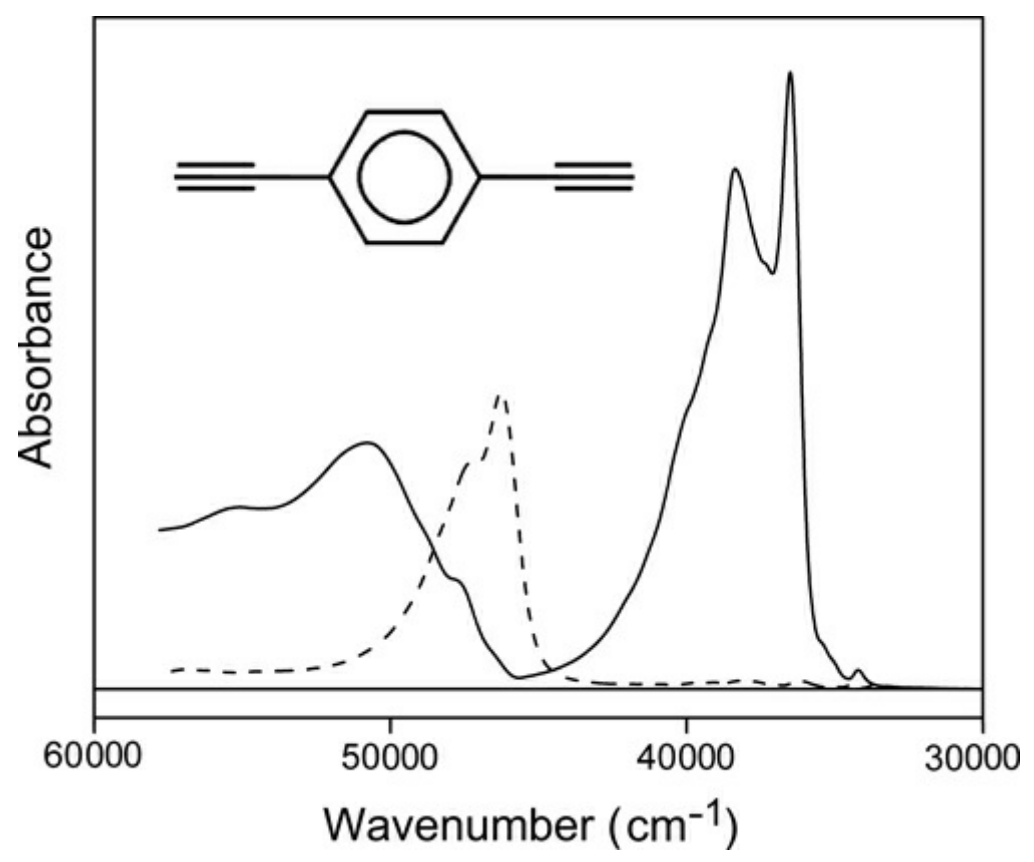

\section{KEYWORDS}

- Ethymylarenes

- electronic transitions

- synchrotron radiation

- linear dichroism (LD)

- time-dependent density functional theory (TD-DFT)

- Rydberg orbitals[Q2]

\section{FUNDING}

This work was supported by Grants of beam time on the CD1 beamline at ISA[Q3][Q4].

\section{Introduction}

1,4-diethynylbenzene (DEB, Scheme 1) is important as a monomer or a precursor for the highly conjugated polymers poly(diethynylbenzene) (PDEB) and poly(phenylene butadiynylene) (PPB) and as a structural element in a variety of molecular networks and electronic devices [1-14]. The optical and photophysical properties of DEB have been the subject of several studies. The UV absorption spectrum was investigated extensively by van Putten [15] with analyses of the vibronic fine structure. The UV photoelectron spectrum of DEB and several related ethynyl compounds were published by Brogli et al. [16]. The IR spectrum and the vibrational modes were studied by van Putten [15], King and van Putten [17], and by Arenes et al. [18]. Stearns and Zwier [19] performed IR and UV experiments on jet-cooled DEB. The emission spectra of DEB were published by Sazhnikov et al. [20] and by Stang and coworkers [21] in studies of photophysical processes, and Levitus et al. [22] studied the photophysical properties of the fluoro-derivative of DEB. The vibronic structure of the low temperature fluorescence spectrum was analyzed by Laposa [23].

Scheme 1. 1,4-Diethynylbenzene (DEB) with definition of the molecular coordinate system.
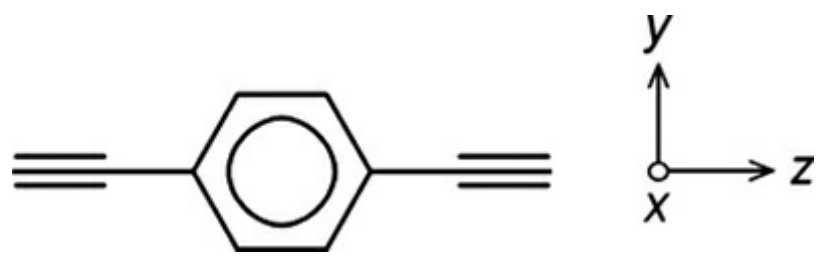

In the present publication we report the results of an investigation of the excited electronic states of DEB by UV Linear Dichroism (LD) spectroscopy on molecular samples dissolved and partially aligned in stretched low-density polyethylene (PE). LD polarisation spectroscopy [24-27] provides information on the transition moment directions of the observed absorption bands, leading to resolution of otherwise overlapping spectral features and to experimental symmetry assignments of the observed states. The use of synchrotron radiation provides increased signal-to-noise ratio in the UV region [28,29]. This enables a substantial expansion of the accessible spectral range, compared with the use of a traditional light source [30]. The present measurement is thus extended into the vacuum UV, covering the spectral region up to about $58,000 \mathrm{~cm}^{-1}(170 \mathrm{~nm})$. The observed transitions are compared with the results of previous investigations and are discussed with reference to electronic transitions predicted with calculational procedures, including Time-Dependent Density Functional Theory (TD-DFT) [31]. Additional 


\section{Experimental}

\subsection{Sample preparation}

A sample of DEB (CAS No. 935-14-8) was purchased from Sigma-Aldrich, No. 632090. The spectroscopic purity was checked by comparison with literature IR and UV spectra $[15,17]$. UV absorbance spectra of the substance in $n$-heptane solution (Merck UVASOL) and in the gas phase are shown in S1 and S2. Low-density polyethylene (PE) was obtained from two sources: $100 \mu \mathrm{m}$ sheet material from Hinnum Plast A/S, and ca. $1.9 \mathrm{~mm}$ thick material cut from laboratory bottles of low-density PE, Kartell Art. 1618. The PE was purified by extraction with chloroform (Merck Uvasol) at $50{ }^{\circ} \mathrm{C}$ for several days. DEB was introduced into the dried PE material by sublimation in a sealed container at room temperature for $1-4$ days, producing a solution of the substance in the polymer medium. The surfaces of the doped sample were cleaned with methanol (Merck Uvasol) to remove crystalline deposits. The samples were uniaxially stretched by ca. $500 \%$. The thickness of the samples after stretching was ca. $0.05 \mathrm{~mm}$ for the thin and $0.6 \mathrm{~mm}$ for the thick material. Samples without solute were produced in the same manner for use as references. Further details on stretched PE samples can be found in the literature [24,25].

\subsection{Linear Dichroism (LD) spectroscopy}

LD spectra in the range 31,300-25,000 $\mathrm{cm}^{-1}(320-400 \mathrm{~nm})$ were recorded on a UV-2600 Shimadzu spectrophotometer at Roskilde University. SRLD spectra were measured in the range 58,000-27,000 $\mathrm{cm}^{-1}(170-360 \mathrm{~nm})$ on the CD1 beamline [28,29] at the storage ring ASTRID at the Centre for Storage Ring Facilities (ISA). Two linear dichroic absorbance curves $\left\{E_{-} U\right\}$ ( $\{\backslash$ tilde $\{\backslash n u\}\}$ ) and $\left\{E_{-} V\right\}(\{\backslash$ tilde $\{\backslash n u\}\}$ ) were recorded with linearly polarised radiation at room temperature with the electric vector of the sample beam parallel $(U)$ and perpendicular $(V)$ to the stretching direction of the PE sample. The baseline-corrected absorbance curves $\left\{E_{-} U\right\}(\{\backslash$ tilde $\{\backslash n u\}\})$ and $\left\{E_{-} V\right\}(\{\backslash$ tilde $\{\backslash n u\}\})$ are shown in S3. Partial absorbance curves $\left\{A_{-} y\right\}(\{\backslash$ tilde $\{\backslash n u\}\}$ ) and $\left\{A_{-} z\right\}(\{\backslash$ tilde $\{\backslash n u\}\}$ ) corresponding to intensity polarised along the molecular axes $y$ and $z$ (Scheme 1 ) were derived as linear combinations of $\left\{E_{-} U\right\}(\{\backslash$ tilde $\{\backslash n u\}\})$ and $\left\{E_{-} V\right\}(\{\backslash$ tilde $\{\backslash n u\}\})$ as previously described [24,25,32], see S3 for details. The partial absorbance curves $\left\{A_{-} y\right\}\left(\{\backslash\right.$ tilde $\{\backslash n u\}\}$ ) and $\left\{A_{-} z\right\}(\{\backslash$ tilde $\{\backslash n u\}\})$ are shown in Figures 1 and 2 and observed spectral features are listed in Tables 1 and 2.

Figure 1. Partial absorbance curves $\left\{A_{-} y\right\}(\{\backslash t i l d e\{\backslash n u\}\})$ and $\left\{A_{-} z\right\}(\{\backslash$ tilde $\{\backslash n u\}\}$ ) for 1,4-diethynylbenzene (DEB) dissolved and aligned in stretched polyethylene (PE). The curves indicate absorbance polarised along the molecular $y$ and $z$ axes, derived from linear dichroic absorbance spectra $\left\{E_{-} U\right\}\left(\{\backslash\right.$ tilde $\{\backslash n u\}\}$ ) and $\left\{E_{-} V\right\}(\{\backslash$ tilde $\{\backslash n u\}\}$ ) measured at room temperature with synchrotron radiation on a stretched polyethylene sample, thickness ca. $0.05 \mathrm{~mm}$ (S3).

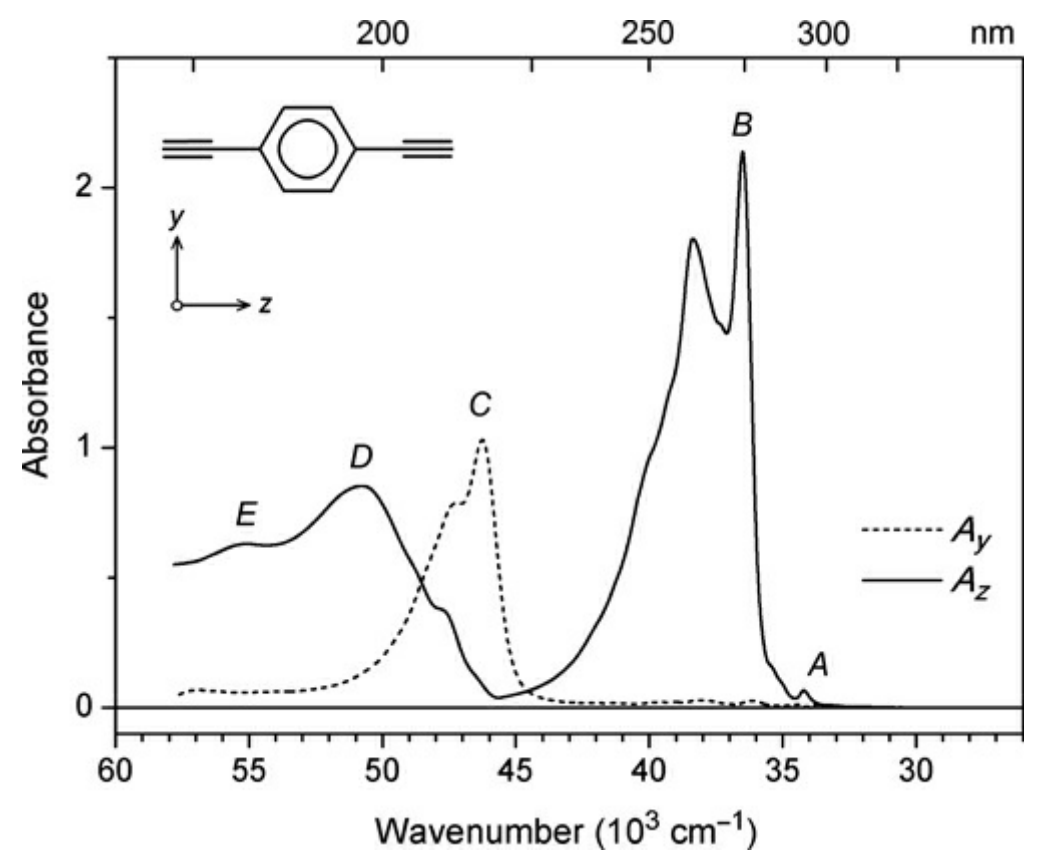

Figure 2. Partial absorbance curves $\left\{A_{-} y\right\}(\{\backslash$ tilde $\{\backslash n u\}\})$ and $\left\{A_{-} z\right\}(\{\backslash$ tilde $\{\backslash n u\}\})$ for 1,4-diethynylbenzene (DEB) dissolved and aligned in stretched polyethylene (PE), covering the region of band $A$ with indication of wavenumbers of absorbance maxima. The curves indicate absorbance polarised along the molecular $y$ and $z$ axes, derived from linear dichroic absorbance spectra $\left\{E_{-} U\right\}(\{\backslash$ tilde $\{\backslash n u\}\})$ and $\left\{E_{-} V\right\}(\{\backslash$ tilde $\{\backslash n u\}\})$ recorded at room temperature with a UV-2600 Shimadzu spectrophotometer on a stretched polyethylene sample, thickness $0.6 \mathrm{~mm}(\mathrm{~S} 3)$. 


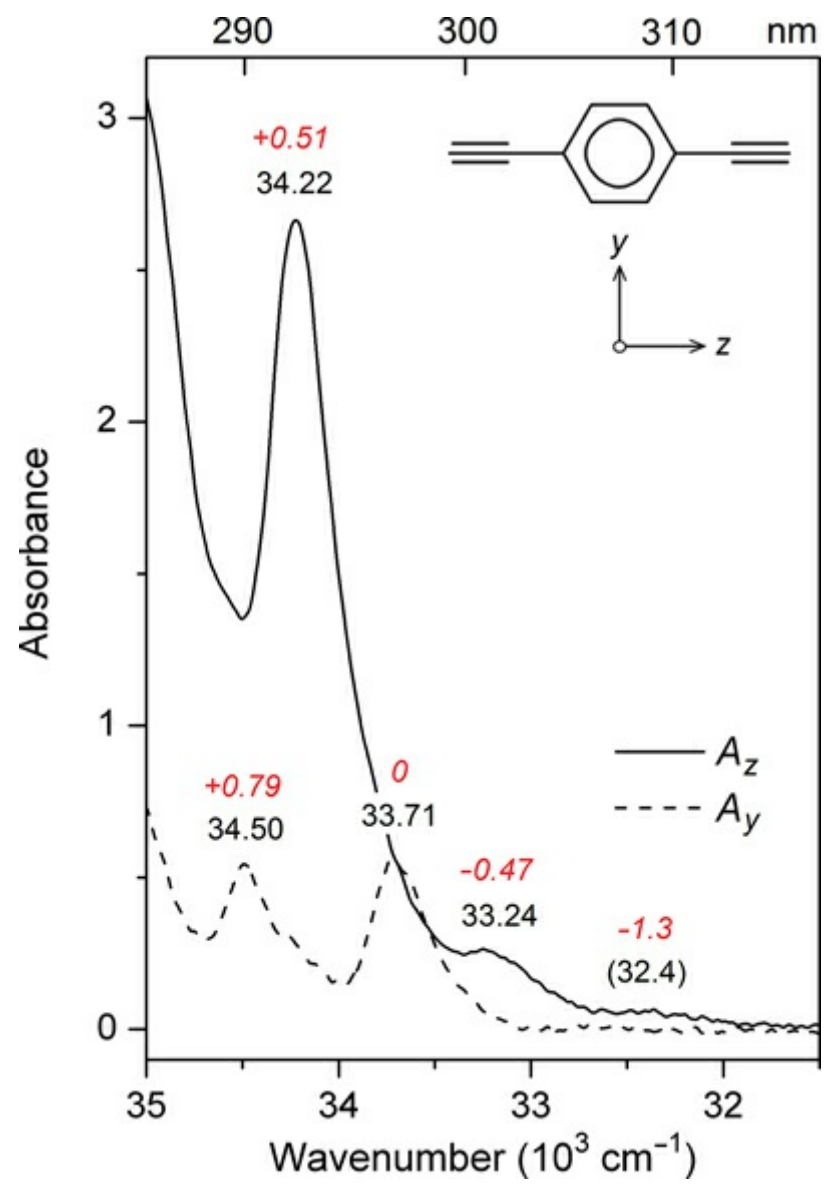

Table 1. Observed features of the SRLD spectrum of 1,4-diethynylbenzene (DEB) and vertical electronic transitions predicted with TD-CAM-B3LYP.

\begin{tabular}{|c|c|c|c|c|c|c|c|}
\hline \multicolumn{4}{|c|}{ Observed } & \multicolumn{4}{|c|}{ TD-CAM-B3LYP/AUG-cc-pVTZ ${ }^{a}$} \\
\hline & $\backslash$ tilde $\{\backslash n u\}^{b}$ & $\mathrm{Abs}^{\mathrm{c}}$ & $\mathrm{Pol}^{\mathrm{d}}$ & Term $^{e}$ & $\backslash$ tilde $\{\backslash n u\}^{\mathrm{b}, \mathrm{d}}$ & $f^{g}$ & Leading configurations $^{\mathrm{h}}$ \\
\hline \multirow{2}{*}{$A$} & \multirow{2}{*}{$33.7^{i}$} & \multirow{2}{*}{-} & \multirow{2}{*}{$y$} & \multirow{2}{*}{$1{ }^{1} B_{2 u}\left(L_{b}\right)$} & \multirow{2}{*}{37.3} & \multirow{2}{*}{$2 \cdot 10^{-3}$} & $50 \%\left[2 b_{2 g}(\pi) \rightarrow 1 a_{\mathrm{u}}\left(\pi^{\star}\right)\right]$ \\
\hline & & & & & & & $47 \%\left[1 b_{1 g}(\pi) \rightarrow 3 b_{3 u}\left(\pi^{\star}\right)\right]$ \\
\hline$B$ & 36.5 & 2.2 & $z$ & $1{ }^{1} B_{1 u}\left(L_{a}\right)$ & 36.0 & 0.62 & $92 \%\left[2 b_{2 g}(\pi) \rightarrow 3 b_{3 u}\left(\pi^{\star}\right)\right]$ \\
\hline \multirow{2}{*}{ C } & \multirow{2}{*}{46.3} & \multirow{2}{*}{1.1} & \multirow{2}{*}{$y$} & \multirow{2}{*}{$2{ }^{1} B_{2 u}\left(B_{b}\right)$} & \multirow{2}{*}{46.9} & \multirow{2}{*}{0.25} & $50 \%\left[1 b_{1 g}(\pi) \rightarrow 3 b_{3 u}\left(\pi^{\star}\right)\right]$ \\
\hline & & & & & & & $48 \%\left[2 b_{2 g}(\pi) \rightarrow 1 a_{\mathrm{u}}\left(\pi^{\star}\right)\right]$ \\
\hline \multirow[t]{2}{*}{$D$} & \multirow[t]{2}{*}{50.8} & 0.9 & $z$ & $2{ }^{1} B_{1 u}\left(B_{a}\right)$ & 51.0 & 0.45 & $83 \%\left[1 b_{1 \mathrm{~g}}(\pi) \rightarrow 1 a_{\mathrm{u}}\left(\pi^{\star}\right)\right]$ \\
\hline & & & & $3{ }^{1} \mathrm{~B}_{1 \mathrm{u}}$ & 54.9 & 0.06 & $75 \%\left[2 b_{2 g}(\pi) \rightarrow 4 b_{3 u}\left(3 p_{\pi}\right)\right]$ \\
\hline \multirow{4}{*}{$E$} & \multirow{4}{*}{55.2} & \multirow{4}{*}{0.6} & \multirow{4}{*}{$z$} & \multirow{4}{*}{$4{ }^{1} \mathrm{~B}_{1 \mathrm{u}}$} & \multirow{4}{*}{56.2} & \multirow{4}{*}{0.54} & $23 \%\left[1 b_{2 g}(\pi) \rightarrow 3 b_{3 u}\left(\pi^{\star}\right)\right]$ \\
\hline & & & & & & & $18 \%\left[2 b_{2 g}(\pi) \rightarrow 4 b_{3 u}\left(3 p_{\pi}\right)\right]$ \\
\hline & & & & & & & $11 \%\left[5 b_{2 u}\left(\pi_{C \equiv C}\right) \rightarrow 6 b_{3 g}\left(\pi_{C} \equiv C^{\star}\right)\right]$, \\
\hline & & & & & & & $10 \%\left[4 b_{3 g}\left(\pi_{C \equiv C}\right) \rightarrow 7 b_{2 u}\left(\pi_{C} \equiv C^{\star}\right)\right]$ \\
\hline
\end{tabular}

a Main transitions only. Complete lists of calculated transitions provided as supplemental data S7.

b Peak wavenumber in $1000 \mathrm{~cm}^{-1}$. $X$

c Peak absorbance estimated from the partial absorbance curves in Figure 1. $\chi$

dPolarisation direction. $X$

${ }^{e} L_{b}, L_{a}, B_{b}$, and $B_{a}$ refer to Platt's nomenclature [52]. [32]. $X$

${ }^{f}$ An em pirical correction of $3000 \mathrm{~cm}^{-1}$ is subtracted from the calculated wavenumber. 
$\mathrm{h}_{\mathrm{MO}}$ energies and surface diagrams in Figures 3 and $4 . X$

Table 2. Components of the $1^{1} B_{2 u}\left(L_{b}\right)$ electronic transitions in 1,4-diethynylbenzene (DEB).

\begin{tabular}{|c|c|c|c|c|c|}
\hline$\backslash$ tilde $\{\backslash n u\}^{a, b}$ & $\backslash$ tilde $\{\backslash n u\}^{a, c}$ & $\backslash$ tilde $\{\backslash n u\}^{a, d}$ & Assign $^{e}$ & Mode $^{f}$ & Description $^{f}$ \\
\hline $33,240(z)$ & 33,712 & - & 20_1^0 & $\left\{\backslash n u \_\{20\}\right\}\left(b_{3 g}\right)$ & $\backslash$ beta $(C-C \equiv C)^{9}$ \\
\hline $33,710(y)$ & 34,250 & 34,255 & $0 \_0^{\wedge} 0$ & - & - \\
\hline $34,220(z)$ & 34,739 & 34,747 & $20 \_0^{\wedge} 1$ & $\left\{\backslash n u \_\{20\}\right\}\left(b_{3 g}\right)$ & $\backslash$ beta $(C-C \equiv C)^{9}$ \\
\hline $34,500(y)$ & 35,010 & 35,015 & 7_0^1 & $\left\{\backslash n u_{-} 7\right\}\left(a_{\mathrm{g}}\right)$ & $\ln u(C-C)^{h}$ \\
\hline
\end{tabular}

a Peak maximum in $\mathrm{cm}^{-1}$. $\mathrm{X}$

c Gas phase data [15]. $\chi$

dGas phase data [19]. $X$

e Vibronic assignment [15,19]. $X$

${ }^{\mathrm{f}}$ Numbering and description according to Ref. [17]. $X$

${ }^{\mathrm{b}}$ Stretched PE, polarisation direction in parentheses (Figure 2). $X$

g $\mathrm{C}-\mathrm{C} \equiv \mathrm{C}$ bending. $X$

${ }^{\mathrm{h}}$ Ring deformation. $X$

\section{Calculations}

Quantum chemical CAM-B3LYP, TD-CAM-B3LYP [33], CIS [34] and CIS(D) [35,36] calculations were performed with the Gaussian16 software package $[31,37]$, using the basis set AUG-cc-pVTZ $[38,39]$. We have recently applied CAM-B3LYP and TD-CAM-B3LYP with success for a number of conjugated compounds [30,40], and the CIS(D) method was recommended by Grimme and Izgorodina [41] for prediction of the $0-0$ excitation energies of organic chromophores, including DEB.

The ground state molecular equilibrium geometry was calculated with CAM-B3LYP. Atomic coordinates and vibrational modes are given in S4. MO surface diagrams were produced with GaussView 6 [42] using a constant isovalue equal to 0.022. Important orbitals are shown in Figures 3 and 4. Equilibrium geometries and vibrational modes for the two lowest excited singlet states were calculated with TD-CAM-B3LYP, the results are provided in S5 and S6.

Figure 3. Energies (eV) and surface diagrams of important MOs of 1,4-diethynylbenzene (DEB) computed with CAMB3LYP/AUG-cc-pVTZ. The $4 b_{3 u}\left(3 p_{\pi}\right)$ orbital (No. 43) is viewed from a different angle in Figure 4. 


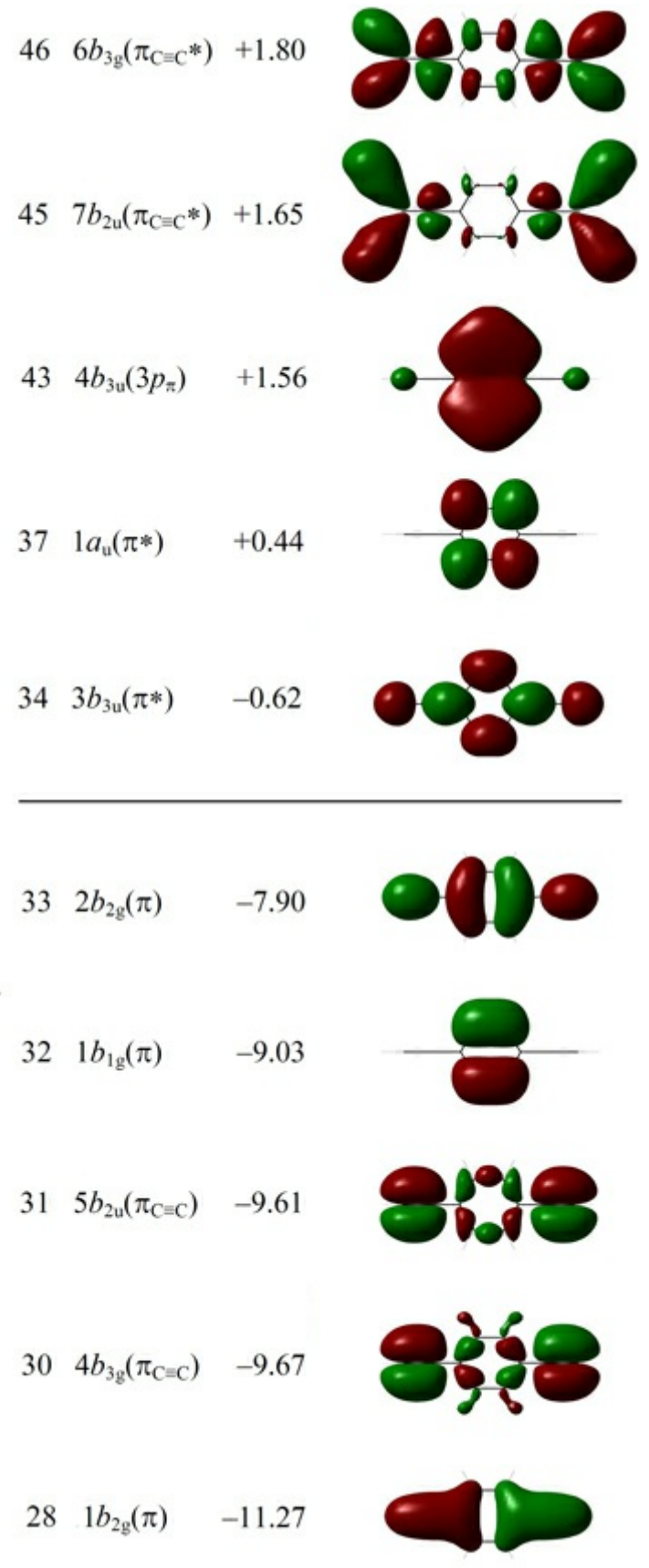

Figure 4. Different view of the $4 b_{3 u}\left(3 p_{\pi}\right)$ molecular orbital of 1,4-diethynylbenzene (DEB) computed with CAMB3LYP/AUG-cc-pVTZ. 


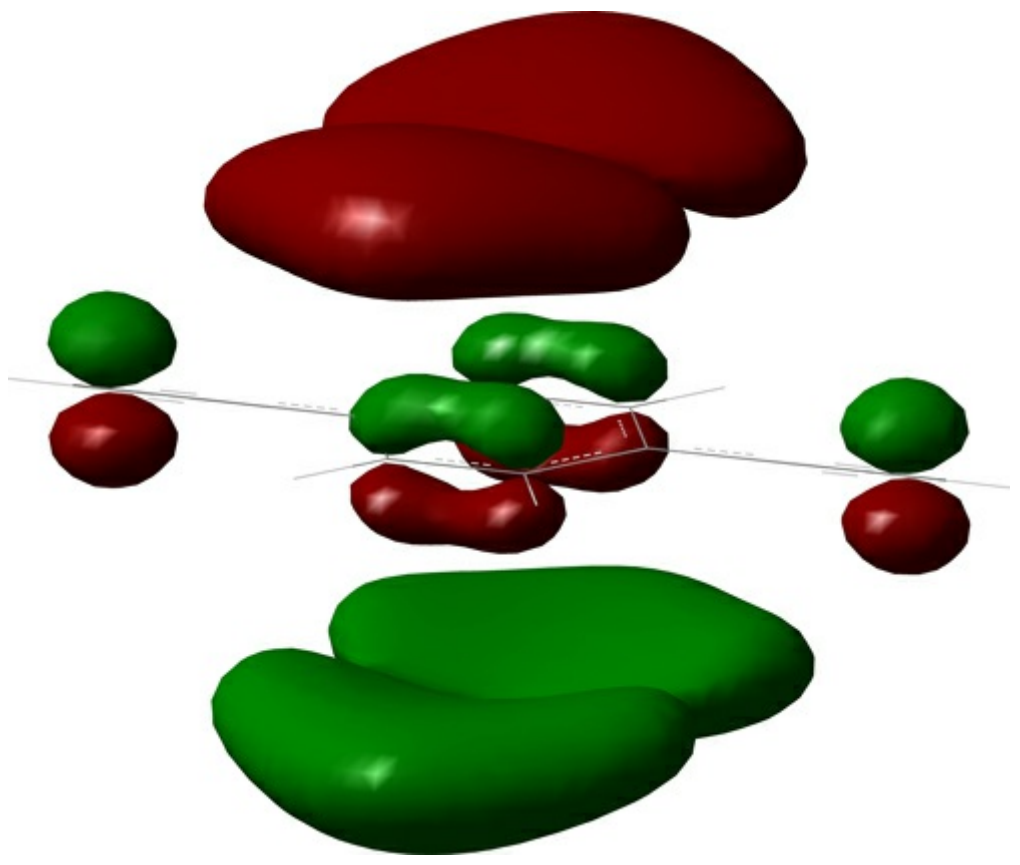

Vertical electronic transitions from the ground state to the 50 lowest excited singlet states were computed with TD-CAM-B3LYP, CIS and CIS(D). The main transitions predicted with TD-CAM-B3LYP are listed in Table 1; an empirical correction of $3000 \mathrm{~cm}^{-1}$ is subtracted from the calculated excitation wavenumbers in order to facilitate comparison with the observed spectra [30,43]. Complete listings of the transitions predicted with TD-CAM-B3LYP, CIS, and CIS(D) are provided in S7 and S8.

Additional calculations were carried out with the Linear Combination of Orthogonalized Atomic Orbitals (LCOAO) method [4446]. This semiempirical all-valence-electrons procedure was developed for the prediction of electronic transitions and Magnetic Circular Dichroism (MCD) B-terms [47] for conjugated organic compounds. It has been applied to several conjugated hydrocarbons containing triple-bonded linkages $[45,48,49]$. The LCOAO results are listed in $\mathrm{S} 9$.

\section{Results and discussion}

\subsection{Middle UV}

The middle UV spectrum is characterised by a weak absorbance band $A$ starting around $34,000 \mathrm{~cm}^{-1}$ (294 nm), overlapping a much stronger $z$-polarised band $B$ with maximum at $36,500 \mathrm{~cm}^{-1}(274 \mathrm{~nm})$. The bands $A$ and $B$ must be assigned to the states 1 ${ }^{1} B_{2 u}\left(L_{b}\right)$ and $1{ }^{1} B_{1 u}\left(L_{a}\right)$, respectively, see Table 1 , consistent with previous assignments $[15,19,23]$. TD-CAM-B3LYP (Table $1, S 7$ ) and CIS (S8) predict the opposite ordering of the two states, namely $L_{b}$ above $L_{a}$. Optimisation of the excited state geometries with TD-CAM-B3LYP does not change the predicted ordering [S5,S6]. But as shown by Grimme and Izgorodina [41], the inclusion of doubles and triples corrections in the CIS(D) procedure (S8) leads to reordering of the $L$ states, resulting in $L_{b}$ as the lowest excited singlet state of DEB, as observed. LCOAO (S9) predicts $L_{b}$ at 35,500 and $L_{a}$ at $37,000 \mathrm{~cm}^{-1}$, with positive and negative electronic MCD $B$-terms, respectively.

Detailed assignment of the differently polarised components of band $A$ needs particular attention (Figure 2). The $y$-polarised peak at $33,710 \mathrm{~cm}^{-1}(297 \mathrm{~nm})$ must be assigned to the $0-0$ component of the $1^{1} \mathrm{~B}_{2 \mathrm{u}}\left(\mathrm{L}_{\mathrm{b}}\right)$ state. Laposa [23] assigned a corresponding peak at $33,805 \mathrm{~cm}^{-1}(296 \mathrm{~nm})$ to the $0-0$ component of the fluorescence emission spectrum in a hydrocarbon matrix at $77 \mathrm{~K}$. The additional peaks in this region can be assigned to vibronic components. The 'hot band' at $33,240 \mathrm{~cm}^{-1}(301$ $\mathrm{nm}$ ) and the 'false origin' at $34,220 \mathrm{~cm}^{-1}(292 \mathrm{~nm}$ ) are both $z$-polarised. They can be assigned to vibronic components involving excitation of a non-totally symmetric vibration of $b_{3 g}$ symmetry, thereby gaining $z$-polarised intensity by coupling with the strong $B$ band. The $y$-polarised feature at $34,500 \mathrm{~cm}^{-1}(290 \mathrm{~nm})$ can be assigned to a component involving a totally symmetric vibration $\left(a_{\mathrm{g}}\right)$.

In Table 2, the observed wavenumbers in the region of band $A$ are compared with gas phase data from the literature [15,19]; the gas phase wavenumbers are shifted by ca. $500 \mathrm{~cm}^{-1}$ relative to those measured in stretched PE. The present polarisation data support the previous vibronic analyses by van Putten [15] and by Stearns and Zwier [19], involving the $C-C \equiv C$ bending mode $\left\{\backslash n u_{-}\{20\}\right\}\left(b_{3 g}\right)$ and the ring deformation mode $\left\{\backslash n u_{-} 7\right\}\left(a_{\mathrm{g}}\right)$. In addition, we observe very weak and diffuse $z$-polarised intensity around $32,400 \mathrm{~cm}^{-1}(309 \mathrm{~nm})$, see Figure 2. This absorption was reproducible in our experiments, but it cannot be excluded that it is due to a trace impurity. It could possibly be due to an additional 'hot band' involving $b_{3 g}$ symmetrical vibrations such as $\left\{\backslash n u \_\{16\}\right\}\left(b_{3 g}\right)$ or $\left\{\backslash n u \_\{17\}\right\}\left(b_{3 g}\right)[17]$.

Further analysis of band $A$ is complicated by overlap with the much stronger band $B$, but the gas phase spectrum reveals 
additional detail $[15,19]$. Van Putten [15] has suggested assignments of more than a dozen vibronic features to a variety of vibrational fundamentals and summation levels. He has also analyzed the rich vibronic fine structure of band $B$, involving primarily the $\mathrm{C} \equiv \mathrm{C}$ stretching mode $\left\{\backslash \mathrm{nu} \_3\right\}\left(a_{\mathrm{g}}\right)$ and the ring deformation mode $\left\{\backslash n u_{-} 7\right\}\left(a_{\mathrm{g}}\right)[15,17]$.

\subsection{Far UV}

The $58,000-45,000 \mathrm{~cm}^{-1}(170-220 \mathrm{~nm})$ region of the spectrum of DEB has apparently not been analyzed previously. The present polarisation spectra lead to resolution of the absorbance into two differently polarised contributions: an intense $y$-polarised band $C$ at $46,300 \mathrm{~cm}^{-1}(216 \mathrm{~nm})$ with partly resolved vibrational fine structure, followed by a broad $z$-polarised absorption band with maxima $D$ and $E$ at 50,800 and 55,200 $\mathrm{cm}^{-1}$ (197 and $181 \mathrm{~nm}$ ), see Figure 1 and Table 1.

The features $C$ and $D$ are easily assigned to the states $2{ }^{1} B_{2 u}\left(B_{b}\right)$ and $2{ }^{1} B_{1 u}\left(B_{a}\right)$ predicted at 46,900 and $51,000 \mathrm{~cm}^{-1}$ by TDCAM-B3LYP. CIS (S8) predicts the opposite ordering of the B states, but the corrections in CIS(D) leads to large shifts (S8), resulting in $B_{b}$ below $B_{a}$. LCOAO (S9) predicts $B_{b}$ and $B_{a}$ at 48,900 and $53,700 \mathrm{~cm}^{-1}$ with negative and positive electronic MCD $B$ terms, respectively.

TD-CAM-B3LYP predicts additional z-polarised transitions to the states 3 and $4{ }^{1} \mathrm{~B}_{1 \mathrm{u}}$ at 54,900 and 56,200 $\mathrm{cm}^{-1}$ (Table 1 ). The broad absorption band with maximum $E$ at $55,200 \mathrm{~cm}^{-1}(181 \mathrm{~nm})$ can probably be assigned to these transitions. The prediction of these transitions depends on the inclusion of diffuse functions in the basis set. Both states involve promotion from the $2 b_{2 g}(\pi)$ $\mathrm{HOMO}$ to the virtual MO $4 b_{3 \mathrm{u}}$ which is of mixed valence-Rydberg character. In Table 1 and in Figures 3 and 4 , this $\mathrm{MO}$ is characterised as $3 p_{\pi}$. The optically intense $4^{1} B_{1 u}$ state predicted at $56,200 \mathrm{~cm}^{-1}$ involves several additional configurations, such as $5 b_{2 u}\left(\pi_{C \equiv C}\right) \rightarrow 6 b_{3 g}\left(\pi_{C \equiv C^{*}}\right)$ and $4 b_{3 g}\left(\pi_{C \equiv C}\right) \rightarrow 7 b_{2 u}\left(\pi_{C \equiv C^{*}}\right)$ which indicate promotions involving the in-plane $\pi$ and $\pi^{\star}$ components of the $C \equiv C$ triple bonds. The surface diagrams in Figure 3 show that the virtual $7 b_{2 u}\left(\pi_{C \equiv C^{*}}\right)$ and $6 b_{3 g}\left(\pi_{C} \equiv C^{\star}\right)$ MOs have considerable diffuse character. Investigation of the transitions in the high wavenumber region with more advanced theoretical procedures, for example like those applied by Christiansen et al. [50] and Hashimoto et al. [51] in their studies of the electronic states of benzene, would probably be rewarding.

\section{Conclusions}

This publication reports the results of an LD spectroscopic investigation of DEB dissolved and partially aligned in a stretched PE matrix, yielding UV polarisation data for transitions in the region ranging from the onset of the absorption around $32,000 \mathrm{~cm}^{-1}$ $(310 \mathrm{~nm})$ to $58,000 \mathrm{~cm}^{-1}(170 \mathrm{~nm})$ in the far UV. The observed polarisation directions for the components of the weak absorption between 32,000 and $35,000 \mathrm{~cm}^{-1}$ (310 and $285 \mathrm{~nm}$ ) support previous vibronic assignments by van Putten [15] and by Stearns and Zwier [19]. The LD spectra in the region 45,000-58,000 cm-1 (220-170 nm) reveal previously unobserved, differently polarised features. The new information allows unambiguous assignments of the $y$ - and $z$-polarised $B_{b}$ and $B_{a}$ transitions. An additional, broad z-polarised absorption band peaking at 55,200 cm-1 (181 nm) is probably due to transitions with large non-valence character (see below).

The observed transitions are compared with the results of theoretical procedures. Assignment of the $L$ and $B$ bands is relatively straightforward and the sequence $L_{b}, L_{a}, B_{b}, B_{a}$ seems well established. But TD-CAM-B3LYP and CIS predict the reversed ordering of the closely spaced $L_{b}$ and $L_{a}$ bands, and CIS also predicts the reversed ordering of the two $B$ bands. Inclusion of the corrections terms in CIS(D) leads to agreement with the experimental sequence of all four $L$ and $B$ bands. LCOAO predicts the sequence $L_{b}$, $L_{a}$, $B_{b}, B_{a}$ with positive, negative, negative and positive electronic MCD $B$-terms, respectively.

According to TD-CAM-B3LYP, the absorption in the far UV with a maximum at $55,200 \mathrm{~cm}^{-1}$ (181 nm) can be assigned to transitions involving virtual MOs of diffuse character, such as the $4 b_{3 u}$ orbital which is computed to have mixed valence-Rydberg nature $\left(\sim 3 p_{\pi}\right)$. Also excitations involving the in-plane $\pi$ and $\pi^{*}$ components of the $C \equiv C$ triple bonds contribute strongly to the transitions predicted in this region. Application of more advanced theoretical procedures may throw additional light on the electronic states of DEB in this spectral region.

\section{Acknowledgments}

This project was supported by grants of beam time on the CD1 beamline at ISA. The authors are grateful to J. B. BøgelundNielsen, C. Brydegaard Rasmussen, H. Gram, and B. Haldrup for preliminary UV measurements, and to Eva M. Karlsen for assistance in the spectroscopy lab.

\section{Disclosure statement}

No potential conflict of interest was reported by the author(s).

\section{ORCID}




\section{References}

1 R. Giesa, J. Macromol. Sci. Rev. Macromol. Chem. Phys. C36, 631-670 (1996). doi:10.1080/15321799608014857.

2 U.H.F. Bunz, Chem. Rev. 100, 1605-1644 (2000). doi:10.1021/cr990257j.

3 V. S.-Y. Lin, D.R. Radu, M.-K. Han, W. Deng, S. Kuroki, B.H. Shanks and M. Pruski, J. Am. Chem. Soc. 124, $9040-9041$ (2002). doi:10.1021/ja025925o.

4 I. Fratoddi, C. Battocchio, A. Furlani, P. Mataloni, G. Polzonetti and M.V. Russo, J. Organomet. Chem. 674 10-23 (2003). doi:10.1016/S0022-328X(03)00156-6.

5 J.-X. Jiang, F. Su, H. Niu, C.D. Wood, N.L. Campbell, Y.Z. Khimyak and A.I. Cooper, Chem. Commun. 8, 486-468 (2008). doi:10.1039/B715563H.

6 E. Escalante-Sánchez, B. Rodriguez-Molina and M.A. Garcia-Garibay, J. Org. Chem. 77, 7428-7434 (2012). doi:10.1021/jo301223q.

7 D. Czajkowska-Szczykowska, B. Rodriguez-Molina, N.E. Magana-Vergara, R. Santillan, J.W. Morzycki and M.A. GarciaGaribay, J. Org. Chem. 77, 9970-9978 (2012). doi:10.1021/jo3020402.

8 S. Vogelsberg and M.A. Garcia-Garibay, Chem. Soc. Rev. 41, 1892-1910 (2012). doi:10.1039/C1CS15197E.

9 J. Eichhorn, W.M. Hecklabc and M. Lackinger, Chem. Commun. 49, 2900-2902 (2013). doi:10.1039/c3cc40444g.

10 X.-H. Zhang, X.-P. Wang, J. Xiao, S.-Y. Wang, D.-K. Huang, X. Ding, Y.-G. Xiang and H. Chen, J. Catal. 350, 64-71 (2017). doi:10.1016/j.jcat.2017.02.026.

11 T.-H. Le, Y.-H. Choi, K.-J. Kim and H.-D. Jeong, ACS Omega 4, 3133-3145 (2019). doi:10.1021/acsomega.8b03459.

12 H. Sun, C. Neumann, T. Zhang, M. Löffler, A. Wolf, Y. Hou, A. Turchanin, J. Zhang, and X. Feng, Adv. Mater. 31, 1900961 (2019). doi:10.1002/adma.201900961.

13 K. Kim, T. Kang, M. Kim and J. Kim, Appl. Catal. B: Environ. 275, 119107 (2020). doi:10.1016/j.apcatb.2020.119107.

14 G.M. Peters, G. Grover, R.L. Maust, C.E. Colwell, H. Bates, W.A. Edgell, R. Jasti, M. Kertesz and J.D. Tovar, J. Am. Chem. Soc. 142, 2293-2300 (2020). doi:10.1021/jacs.9b10785.

15 A.A.G. van Putten, The Spectra of the Diethynylbenzenes, PhD Dissertation, McMaster University (1974) [https://macsphere.mcmaster.ca/bitstream/11375/14310/1/fulltext.pdf].

16 F. Brogli, E. Heilbronner, J. Wirz, E. Kloster- Jensen, R.G. Bergman, K.P.C. Vollhardt and A.J. Ashe III, Helv. Chim. Acta 52, 2620-2645 (1975). doi:10.1002/hlca.19750580847.

17 G.W. King and A.A.G. van Putten, J. Mol. Spectr. 70, 53-67 (1978). doi:10.1016/0022-2852(78)90008-5.

18 J.F. Arenas, I. Marcos and F.J. Ramirez, Spectrochim. Acta A 45, 781-788 (1989). doi:10.1016/0584-8539(89)80214-4.

19 J.A. Stearns and T.S. Zwier, J. Phys. Chem. A 107, 10717-10724 (2003). doi:10.1021/jp035168w.

20 V.A. Sazhnikov, V.F. Razumov and M.V. Alfimov, Opt. Spectrosc. 44, 196-198 (1978).

21 J.-S. Chen, G.-J. Zhao, T.R. Cook, X.-F. Sun, S.-Q. Yang, M.-X. Zhang, K.-L. Han and P.J. Stang, J. Phys. Chem. A 116, 9911-9918 (2012). doi:10.1021/jp3072475.

22 M. Levitus, G. Zepeda, H. Dang, C. Godinez, T.-A. V. Khuong, K. Schmieder and M. A. Garcia-Garibay, J. Org. Chem. 66, 3188-3195 (2001). doi:10.1021/jo015589e.

23 J.D. Laposa, J. Luminiscence 20, 67-72 (1979). doi:10.1016/0022-2313(79)90024-3.

24 J. Michl and E.W. Thulstrup, Spectroscopy with Polarized Light: solute Alignment by Photoselection, in Liquid Crystals, Polymers and Membranes (VCH-Wiley, Deerfield Beach, FL, 1986, 1995).

25 E.W. Thulstrup and J. Michl, Elementary Polarization Spectroscopy (Wiley-VCH, New York, Weinheim, 1989).

26 A. Rodger and B. Nordén, Circular Dichroism and Linear Dichroism (Oxford University Press, Oxford, UK, 1997).[Q5]

27 B. Nordén, A. Rodger and T. Dafforn, Linear Dichroism and Circular Dichroism: a Textbook on Polarized-Light Spectroscopy (RCS Publishing, Cambridge, UK, 2010).

28 A.J. Miles, S.V. Hoffmann, Y. Tao, R.W. Janes and B.A. Wallace, Spectroscopy 21, 245-255 (2007). doi:10.1155/2007/282713. 29 A.J. Miles, R.W. Janes, A. Brown, D.T. Clarke, J.C. Sutherland, Y. Tao, B.A. Wallace and S.V. Hoffmann, J. Synchrotron Rad. 
30 D.D. Nguyen, N.C. Jones, S.V. Hoffmann and J. Spanget-Larsen, J. Phys. Chem. A 122, 184 (2018); Chem. Phys. 519, 64 (2019); PeerJ Physical Chemistry 1:e5 (2019). doi:10.1021/acs.jpca.7b10442.

31 J.B. Foresman and /E. Frisch, Exploring Chemistry with Electronic Structure Methods, 3rd ed. (Gaussian, Inc., Wallingford, CT, 2015).

32 F. Madsen, I. Terpager, K. Olskær and J. Spanget-Larsen, Chem. Phys. 165, 351-360 (1992). doi:10.1016/0301-0104(92)87050J.

33 T. Yanai, D. Tew and N.A. Handy, Chem. Phys. Lett. 393, 51-57 (2004). doi:10.1016/j.cplett.2004.06.011.

34 J. B. Foresman, M. Head-Gordon, J. A. Pople and M. J. Frisch, J. Phys. Chem. 96 135-149 (1992). doi:10.1021/j100180a030.

35 M. Head-Gordon, R. J. Rico, M. Oumi and T. J. Lee, Chem. Phys. Lett. 219, 21-29 (1994). doi:10.1016/0009-2614(94)00070-0.

36 M. Head-Gordon, D. Maurice and M. Oumi, Chem. Phys. Lett. 246, 114-121 (1995). doi:10.1016/0009-2614(95)01111-L.

37 M.J. Frisch, G.W. Trucks, H.B. Schlegel, G.E. Scuseria, M.A. Robb, J.R. Cheeseman, G. Scalmani, V. Barone, G.A. Petersson, H. Nakatsuji, X. Li, M. Caricato, A.V. Marenich, J. Bloino, B.G. Janesko, R. Gomperts, B. Mennucci, H.P. Hratchian, J.V. Ortiz, A.F. Izmaylov, J.L. Sonnenberg, D. Williams-Young, F. Ding, F. Lipparini, F. Egidi, J. Goings, B. Peng, A. Petrone, T. Henderson, D. Ranasinghe, V.G. Zakrzewski, J. Gao, N. Rega, G. Zheng, W. Liang, M. Hada, M. Ehara, K. Toyota, R. Fukuda, J. Hasegawa, M. Ishida, T. Nakajima, Y. Honda, O. Kitao, H. Nakai, T. Vreven, K. Throssell, J.A. Montgomery, Jr., J.E. Peralta, F. Ogliaro, M.J. Bearpark, J. J. Heyd, E.N. Brothers, K.N. Kudin, V.N. Staroverov, T.A. Keith, R. Kobayashi, J. Normand, K. Raghavachari, A.P. Rendell, J.C. Burant, S.S. Iyengar, J. Tomasi, M. Cossi, J.M. Millam, M. Klene, C. Adamo, R. Cammi, J. W. Ochterski, R.L. Martin, K. Morokuma, O. Farkas, J.B. Foresman and D.J. Fox, Gaussian16, Revision A.03 (Gaussian, Inc., Wallingford, CT, USA, 2016).

38 T.H. Dunning, Jr., J. Chem. Phys. 90, 1007-1023 (1989). doi:10.1063/1.456153.

39 R.A. Kendall, T.H. Dunning, Jr., and R.J. Harrison, J. Chem. Phys. 96, 6796-6806 (1992). doi:10.1063/1.462569.

40 J. Spanget-Larsen, Comp. Theor. Chem. 1164, 112551 (2019). doi:10.1016/j.comptc.2019.112551.

41 S. Grimme and E.I. Izgorodina, Chem. Phys. 305, 223-230 (2004). doi:10.1016/j.chemphys.2004.06.050.

42 R. Dennington, T.A. Keith and J.M. Millam, GaussView, Version 6.0.16 (Semichem Inc., Shawnee Mission, Kansas 66222, USA, 2016).

43 S. Grimme, Rev. Comput. Chem. 20, 153-218 (2004).

44 J. Spanget-Larsen, Croat. Chem. Acta 59, 711-717 (1986).

45 J. Spanget-Larsen, Theor. Chem. Acc. 98, 137-153 (1997). doi:10.1007/s002140050287.

46 J. Spanget-Larsen, LCOAO Computer Program, ResearchGate (2014). doi:10.13140/2.1.3455.6482.

47 J. Michl, Tetrahedron 40, 3845-3934 (1980). doi:10.1016/S0040-4020(01)99999-5.

48 D.D. Nguyen, N.C. Jones, S.V. Hoffmann, S.H. Andersen, P.W. Thulstrup and J. Spanget-Larsen, Chem. Phys. 392, 130-135 (2012). doi:10.1016/j.chemphys.2011.10.036.

49 P.W. Thulstrup, N.C. Jones, S.V. Hoffmann and J. Spanget-Larsen, Chem. Phys. Lett. 559, 35-40 (2013). doi:10.1016/j.cplett.2013.01.005.

50 O. Christiansen, H. Koch, A. Halkier, P. Jørgensen, T. Helgaker and A.S. de Merás, J. Chem. Phys. 105, $6921-6939$ (1996). doi:10.1063/1.471985.

51 T. Hashimoto, H. Nakano and K. Hirao, J. Mol. Struct. (Theochem) 451, 25-33 (1998). doi:10.1016/S0166-1280(98)00156-0.

52 J.R. Platt, J. Chem. Phys. 17, 484-495 (1949). doi:10.1063/1.1747293.[Q6] 